\title{
Capitalismo, Estados Unidos e o tráfico internacional de escravos no século XIX
}

\author{
Ricardo Salles* \\ Universidade Federal do Estado do Rio de Janeiro (Unirio) \\ Rio de Janeiro - Rio de Janeiro - Brasil
}

Resenha de: MARQUES, Leonardo. The United States and the Transatlantic Slave Trade to the Americas, 1776 - 1867. New Haven: London: Yale University Press, 2016. 313 pp.

O tema do livro de Leonardo Marques é a participação dos Estados Unidos no tráfico atlântico de escravos entre a fundação da nação, em 1776, e o fim efetivo desse tráfico para a colônia espanhola de Cuba, em 1867. O livro origina-se da tese de doutorado defendida pelo autor na Universidade de Emory, em 2013. A participação nor-

* Ricardo Henrique Salles é Doutor em História pela Universidade Federal Fluminense (2011). Publicou diversos livros, entre eles Nostalgia Imperia: escravidão e formação da identidade nacional no Brasil do Segundo Reinado. É professor na Universidade Federal do Estado do Rio de Janeiro (Unirio). E-mail: ricardohsalles@gmail.com. 
te-americana no tráfico se deu, em primeiro lugar, pelo fato, menos notado pela historiografia e pelo senso comum, de que os Estados Unidos foram o maior país consumidor de bens produzidos por escravos do século XIX (p. 9-10). Mas essa participação ocorreu também pelo envolvimento de traficantes, comerciantes, seguradores, financistas, construtores navais, capitães e marinheiros norte-americanos no tráfico para o próprio Estados Unidos, até 1808, para o Brasil, até 1850, e para Cuba, até 1867. Tal envolvimento foi tanto legal e aberto, até a abolição do tráfico para os EUA em 1808, quanto mais nebuloso, indireto e, eventualmente, ilegal após essa data. Marques trata ainda das atitudes e políticas implementadas pelo congresso e pelo governo federal norte-americanos a respeito do assunto ao longo desse período.

Com base em diversas fontes arquivísticas nos Estados Unidos, Brasil, Cuba e Grã-Bretanha, da análise dos dados disponíveis sobre o tráfico de escravos africanos no site Slavevoyages e da discussão com a literatura secundária, Leonardo Marques aborda seu tema em seis capítulos, além da introdução e da conclusão: a participação norte-americana no tráfico na era das revoluções, entre 1776 e 1808; o período de transição entre essa última data, em que comércio internacional de escravos tornou-se ilegal nos Estados Unidos, e 1820, quando a legislação contra o tráfico tornou-se mais rigorosa; a consolidação do comércio de contrabando internacional de escravos, entre 1820 e 1850, data da abolição efetiva do tráfico para o Brasil; a participação norte-americana no contrabando para o Brasil, entre 1831 e 1850. Os dois capítulos finais tratam das relações da república escravista com Cuba, entre 1851 e 1858, e da crise dessas relações e da própria escravidão norte-americana entre 1859 e 1867, data em que, finalmente, o tráfico foi abolido para a colônia espanhola.

O assunto não é novo, mas ainda é pouco explorado pela historiografia e só recentemente vem recebendo maior atenção. De acordo com Marques, as seguidas revisões historiográficas sobre a tese de W. E. B. Du Bois, The Supression of the African Slave Trade to the United States of America, 1638-1870, de 1896, que teria inflado os números sobre o comércio internacional de escravos para as Américas em geral e para os Estados Unidos em particular, subestimaram a participação indi- 
reta de cidadãos estadunidenses no tráfico. Assim como a tolerância, quando não a defesa, governamental em relação a essa participação (p. 7-10). Só essa "revisão da revisão", por assim dizer, já recomendariam o livro aqui resenhado, além das novas informações que sua pesquisa traz. Mas, o mais importante é como Leonardo Marques realiza essa revisão, inserindo seu tema nos grandes fluxos e redes mercantis, culturais e políticas em escala mundial que ganharam nova forma e impulso no século XIX. Desse modo, sem que o termo seja empregado, podese dizer que se trata de um trabalho de História Global, novo invólucrocom importantes inovações, sem dúvida - para tratar de temas amplos que foram negligenciados pelas correntes historiográficas dominantes nos últimos trinta anos. Além disso, The United States and the Transatlantic Slave Trade to the Americas adota a perspectiva, primeiramente desenvolvida por Dale Tomich, que considera a escravidão - e o tráfico atlântico - do século XIX como uma Segunda Escravidão. De acordo com essa visão, a escravidão e o tráfico do século XIX não foram uma sobrevivência dos tempos coloniais, mas reconfigurações ainda mais poderosas dessas mesmas instituições, que se desenvolveram em íntima conexão com a nova fase de desenvolvimento da economia e do mercado internacional capitalista e da nova ordem mundial regida pela formação dos Estados Nacionais sob hegemonia britânica.

Essa segunda escravidão nasceu sob impulsos contraditórios. Ela respondeu a um incremento substancial da demanda de determinados produtos - algodão, açúcar e café - ocasionado pelos processos de industrialização, urbanização e intensificação do consumo e do comércio internacional na Grã-Bretanha, em outras regiões da Europa e nos Estados Unidos. Tal incremento da demanda foi um dos fatores que propiciaram o desenvolvimento da escravidão em novas áreas no Sul dos Estados Unidos, em Cuba e no Brasil, especialmente no Vale do Paraíba. O tráfico de escravos, que, mesmo depois de ter sido declarado ilegal, aumentou seu volume conforme se expandia a demanda por bens produzidos por escravos, inseria-se em circuitos comerciais mais amplos que incluíam até mesmo bens produzidos por potências antiescravistas: mosquetes, tecidos e chumbo da Grã-Bretanha; tecidos e conhaque da França; tecidos, tabaco e rum dos Estados Unidos. O 
tráfico também estava inserido na estrutura financeira e comercial internacional com suas letras de câmbio, bolsas de valores e companhias por ações (p. 107). Finalmente, o tráfico era peça integrante do contexto mais amplo de relações das regiões escravistas entre si. É conhecida a presença econômica britânica no Brasil, mas os Estados Unidos não ficavam muito atrás. As relações entre Cuba e Estados Unidos eram intensas, ficando atrás apenas da Grã-Bretanha e França. Tudo isso mostra como as elites das três regiões escravistas estavam integradas no mundo do livre comércio (p. 109).

Paradoxalmente, nesse mesmo período, a escravidão e o tráfico passaram a ser globalmente contestados, em resultado dos desdobramentos diretos ou indiretos da campanha britânica pela abolição do tráfico internacional, datada das últimas décadas do século XVIII, da Independência Americana, da Revolução Francesa e da Revolução Haitiana. Nesse contexto, a defesa do livre comércio e o combate ao tráfico internacional de escravos foram pontos fundamentais na imposição da hegemonia britânica na ordem mundial que emergiu após 1815. Portugal, em seguida o Brasil e Espanha, nação soberana sobre a ilha de Cuba, como potências escravistas que dependiam do fluxo de escravos africanos para sua expansão, resistiram o quanto puderam à pressão britânica pela extinção do tráfico. Apesar de aceitarem formalmente a ilegalidade do tráfico africano em 1820 (império espanhol) e 1830 (Império do Brasil), continuaram praticando-o, em escala ainda mais ampliada, até 1850 (Brasil) e 1867 (império espanhol).

E quanto aos Estados Unidos? A partir dos dados levantados e analisados do site Slavevoyages - uma constante no trabalho - Leonardo Marques nos mostra que, entre 1783 e 1807, último ano em que o comércio de escravos africanos foi permitido para o país, traficantes norte-americanos transportaram pouco mais de 165 mil cativos africanos para a América, grande parte deles destinada ao próprio país. Esses traficantes, contudo, não eram provenientes de portos do Sul escravista, mas da região da Nova Inglaterra, especialmente Bristol e Newport (ambas em Rhode Island), evidenciando uma aliança entre o Sul e o Norte. A estrutura desse comércio era eminentemente nacional, em comparação com o esquema altamente internacionalizado 
que tráfico de contrabando adquiriu a partir da década de 1830 em diante. Traficantes, financiadores, seguradores, capitães, tripulações, praticamente tudo era doméstico. A proibição do tráfico, em 1808, respondeu ao temor do perigo que uma grande massa de africanos poderia representar ao país e atendeu os interesses das áreas escravistas mais antigas, onde a população escrava se reproduzia e crescia naturalmente, que poderiam substituir a oferta externa de cativos para as áreas em expansão (p. 96). Quebrava-se, desse modo, a aliança anterior entre Sul e Norte em torno do tráfico, substituída agora por um novo compromisso entre as duas regiões.

A participação norte-americana no comércio internacional de escravos, contudo, prosseguiu, principalmente através do financiamento do tráfico para Cuba, da venda de navios para traficantes espanhóis, da participação direta de capitães e marinheiros norte-americanos na atividade. Em 1820, uma nova legislação antitráfico foi aprovada, transformando a participação nesse comércio ilícito em crime de pirataria e, portanto, passível de pena de morte. Essa legislação selou o fim da estrutura negreira da Nova Inglaterra que havia florescido entre 1783 e 1808 e que sobrevivera daí em diante alimentando o tráfico para Cuba. A médio prazo, na medida em que o tráfico prosseguiu como contrabando para Cuba e Brasil, a legislação, de acordo com Marques, tornou-se "obstáculo insuperável às possíveis alianças entre as três potências escravistas da América em meados do século XIX” (p. 105) .

Na década de 1830, todas as nações atlânticas haviam abolido formalmente o comércio internacional de escravos. Espanha e Brasil, os dois principais Estados nacionais importadores de escravos tinham assinado acordos bilaterais com a Grã-Bretanha que lhe asseguravam o direito de busca e apreensão de navios suspeitos de prática do ilícito comércio. Não é possível saber a dimensão que o tráfico de escravos africanos teria adquirido caso ele não tivesse sido declarado ilegal e esses acordos não tivessem sido firmados. O que sabemos, contudo, é que, mesmo assim, entre 1831 e 1850, data da proibição efetiva do tráfico pelo governo brasileiro, 240.488 africanos escravizados foram desembarcados em Cuba e 738.198 no Brasil. O tráfico ainda prosseguiu para Cuba até 1867. No todo, entre 1820 e 1860, mais de dois milhões 
de escravos africanos, 20\% do total desembarcado na América entre 1501 e 1867, foram trazidos para o Brasil e Cuba (p. 136).

A participação de cidadãos e companhias norte-americanos nesse tráfico foi significativa. Até 1820, de forma direta, como mencionado acima. A partir dessa data, de maneira mais indireta. Capitães e marinheiros estadunidenses, mas também de outras nacionalidades, inclusive britânicos, participavam do tráfico. Como o governo norte-americano só firmou uma convenção de busca bilateral de navios suspeitos de tráfico com a Grã-Bretanha em 1862, navios com sua bandeira ficavam mais protegidos da fiscalização e da repressão britânicas. Muitos navios norte-americanos transportavam produtos que seriam trocados por escravos até a costa africana. Lá esses produtos eram vendidos a traficantes e os navios voltavam para os portos americanos apenas com lastro. Ou ainda, os navios eram vendidos ou fretados para traficantes, que os utilizavam, com ou sem a bandeira estadunidense, para transportar os cativos para a América. Companhias norte-americanas vendiam e fretavam navios para traficantes, como a firma Maxwell, Wright \& Co., principal exportadora de café do porto do Rio de Janeiro, que manteve essa prática até o início da década de 1840, quando foi pressionada, por representantes diplomáticos de seu país junto ao governo imperial, a cessar essa atividade. Traficantes, frequentemente, lançavam mão das bandeiras dos Estados Unidos, mas também de outros países, como França e Sardenha, para encobrir suas atividades. De qualquer modo, a principal contribuição estadunidense para o tráfico internacional de escravos se deu pelo fornecimento da maioria dos navios utilizados nessa atividade, principalmente no período de contrabando. Entre 1831 e 1840, pouco antes do acordo Webster-Ashburton, entre Grã-Bretanha e Estados Unidos, que intensificou o combate ao tráfico por parte do governo deste último país, navios construídos nos Estados Unidos realizaram 1.070, ou 63\% de todas as viagens de contrabando de escravos nesse período, e transportaram 422.453 escravos africanos para Brasil e Cuba.

No que diz respeito especificamente ao Brasil, Marques contesta a ideia esposada por muitos historiadores, como Seymour Drescher, de que o transporte de metade dos africanos desembarcados no país entre 
1831 e 1850 teria sido feito, por via direta ou indireta, por norte-americanos. Estes historiadores estariam seguindo a avaliação feita nesse sentido pelo representante do governo norte-americano no Brasil em 1850, David Tod. O problema é que nesta avaliação estão desde a venda e a transferência legal de navios para traficantes até a participação direta de capitães no embarque na África. Enquanto essa última forma constituía claramente uma violação das lei antitráfico, as outras formas ocorriam na zona cinzenta que conectava atividades comerciais legítimas com o tráfico. O fato é que, entre 1831 e 1850, 58,2\% dos desembarques de contrabando para o país, transportando 429.939 escravos africanos, foram realizadas em navios fabricados nos Estados Unidos. Navios fabricados no Brasil, por sua vez, fizeram 15,4\% dessas viagens e transportaram 113.569 cativos. Outros 26,4\% das embarcações eram de outras procedências e transportaram 194.600 africanos. Talvez por isso, alguns historiadores tenham considerado, erroneamente, segundo Marques, que os norte-americanos mantiveram-se à frente do tráfico para o Brasil. Na verdade, brasileiros e portugueses controlavam o comércio de contrabando de escravos para o país (p. 141-43). Finalmente, ao considerar esses dados, não se deve perder de vista que os Estados Unidos eram o principal fornecedor de navios para o comércio internacional como um todo. Assim, não seria surpreendente que a maioria das embarcações empregadas no tráfico também tivesse essa mesma proveniência.

Do ponto de vista político, Marques assinala que o governo norte-americano e seus diversos representantes diplomáticos no Brasil entre 1831 e 1850 mostraram-se hesitantes em relação ao tráfico, ora o combatendo com veemência, ora fazendo vistas grossas. Essa hesitação e a resistência do governo estadunidense em assinar uma convenção antitráfico com a Grã-Bretanha não seriam, primordialmente, um sinal da predominância dos interesses escravistas do Sul junto ao governo federal. Respondiam mais a disputas geopolíticas com a Grã-Bretanha e a convicções, relativamente ocasionais, sobre o papel dos Estados Unidos na região em relação ao Império do Brasil e ao tráfico internacional. De qualquer forma, ele conclui que mesmo se uma eventual permissão de revista mútua nos navios suspeitos de tráfico entre Esta- 
dos Unidos e Grã-Bretanha tivesse ocorrido em 1842, e não em 1862, como de fato aconteceu, isso não teria feito diferença significativa nos números do tráfico de contrabando para o Brasil (p. 183).

Em relação a Cuba, a constatação é inversa. A participação norte-americana no tráfico - e na própria escravidão, com diversos cidadãos sendo donos de plantation na ilha - foi muito maior, principalmente a partir da década de 1850. Um número maior de navios e de capitães estadunidenses participaram do contrabando para a colônia espanhola. A bandeira norte-americana também foi mais empregada na atividade. Navios com bandeira estadunidense, em 20 viagens de 97, transportaram 10.528, ou 20,4\% de um total de 51.628 africanos escravizados trazidos para Cuba entre 1851 e 1854. Entre 1855 e 1858, os números quase triplicaram. Embarcações com a bandeira norte-americana trouxeram 33.134, ou 67,45\%, dos 49.167 africanos traficados para Cuba, em 61 de um total de 90 viagens. Traficantes portugueses e espanhóis com representações nos Estados Unidos controlavam o tráfico para a colônia espanhola. Mas, o ponto principal da participação norte-americana no tráfico de contrabando para Cuba era de natureza política. O peso norte-americano no tráfico, sua presença em plantations na ilha e a pequena distância entre Cuba e o Sul fizeram com que o governo estadunidense servisse como poderoso anteparo à intervenção britânica na repressão ao tráfico para Cuba. A proximidade geográfica com o Sul dos Estados Unidos, assim como a forte presença de interesses norte-americanos diretamente na colônia espanhola, por sua vez, traziam sempre a ameaça de anexação da ilha à república. Possibilidade que a Grã-Bretanha buscava evitar não minando completamente a autoridade espanhola na colônia. Nessa situação, as autoridades espanholas equilibravam-se em uma corda bamba no jogo geopolítico entre Estados Unidos e Grã-Bretanha (p. 191).

De todo esse panorama, traçado com maestria pelo historiador brasileiro, emerge um quadro complexo que enriquece nosso conhecimento sobre as relações entre escravidão, tráfico e capitalismo no século XIX. Isso não de um ponto de vista teórico, mas a partir das relações concretas entre as classes, elites e governos nacionais que protagonizaram essas relações. Emerge também a constatação do papel 
central dos Estados Unidos nesse cenário e o significado da Guerra da Secessão como ponto de virada na sorte da escravidão naquele país, mas também em Cuba e no Império do Brasil.

Esperamos que a tradução do livro para o português, imprescindível para o estudioso da escravidão do século XIX, venha logo.

Recebido: 21/11/2017 - Aprovado: 03/12/2017 